\title{
Voluntary wheel running promotes myelination in the motor cortex through Wnt signaling in mice
}

\author{
Jian Zheng ${ }^{1,2}$, Xuan Sun ${ }^{1}$, Chaolin Ma', Bao-ming Li1 ${ }^{1 *}$ and Fei Luo ${ }^{1 *}$
}

\begin{abstract}
Myelin of the central nervous system exhibits strong plasticity, and skill learning exercise promotes oligodendrogenesis and adaptive myelination. Increasing evidence shows that brain structures and functions are affected by physical activity. However, the impact of voluntary physical activity on central myelination and its underlying mechanism remains unclear. The present study aimed to investigate the effect of voluntary wheel running (WVR) on central oligodendrogenesis and adaptive myelination in mice. Adult C57BL/6 J mice were placed in running wheels and allowed for voluntary running 2 weeks. Myelin levels in the central nervous system were detected using western blotting, qRT-PCR, immunohistochemical staining, and electron microscopy. Oligodendrocyte precursor cells (OPCs) and oligodendrocytes (OLs) were detected using immunohistochemical staining and 5-bromo-2-deoxyuridine (BrdU) assays. Motor abilities of the animals were examined using open-field, rotarod running, and beam-walking behavioral paradigms. Vital molecules of Wnt signaling were detected, and the involvement of such molecules was verified using in vitro culture of OPCs. Our results showed that WWR significantly enhanced the myelination in the motor cortex. WWR promoted the proliferation and differentiation of OPCs, and the maturation of OLs. The WWR-regulated myelination was associated with the improved motor skill and decreased mRNA level of Wnt3a/9a, whereas stimulation of Wnt signaling pathway with Wnt3a or Wnt9a suppressed OPCs proliferation and differentiation in vitro. The present study demonstrated that physical activity is highly efficient at promoting myelination in the motor cortex, by enhancing the proliferation of OPCs and accelerating the generation of myelin, providing a step forward in understanding the beneficial effects of physical activity on central myelination and its underlying mechanism.
\end{abstract}

Keywords: Voluntary running exercise, Oligodendrocyte, Myelination, Motor functions, Wnt signaling, Mice

\section{Introduction}

Myelin, the multi-laminar sheath that surrounds and insulates axons in the central nervous systems (CNS) and is formed by multipolar glial cells called oligodendrocytes (OLs), greatly facilitates the rapid transmission of neural impulses [1-3]. In humans and non-human primates, myelination persists throughout adulthood in the CNS and involves the generation of new myelinating OLs $[3,4]$. Such prolonged period of myelin development opens a window for individual experiences to influence the myelination $[5,6]$. Compelling evidence indicates that a widespread proliferating population of glial antigen-2 (NG2) or platelet derived growth factor

\footnotetext{
* Correspondence: bmli@ncu.edu.cn; luofei@ncu.edu.cn

'Institute of Life Science, Nanchang University, Nanchang 330031, China

Full list of author information is available at the end of the article
}

receptor alpha (PDGFR $\alpha$ ) positive cells, termed NG2glia or oligodendrocyte precursor cells (OPCs), are the major source of newly generated mature OLs required for myelination $[7,8]$.

Physical activity has beneficial effects on the health of the CNS, and is of great importance for the nervous system to resist diseases and injuries [9]. Previous studies have focused on the changes of various nerve growth factors after exercise and the effects of exercise on neurogenesis $[10,11]$. It is reported that running could promote neurogenesis in the hippocampus [12, 13], and partially reverse aging-associated decline in synapses and neurogenesis [14-16]. Running also enhances synaptic transmission and plasticity, cellular activity in the hippocampus $[10,11,17]$.

(C) The Author(s). 2019 Open Access This article is distributed under the terms of the Creative Commons Attribution 4.0 International License (http://creativecommons.org/licenses/by/4.0/), which permits unrestricted use, distribution, and reproduction in any medium, provided you give appropriate credit to the original author(s) and the source, provide a link to the Creative Commons license, and indicate if changes were made. The Creative Commons Public Domain Dedication waiver (http://creativecommons.org/publicdomain/zero/1.0/) applies to the data made available in this article, unless otherwise stated. 
However, it is unclear whether physical activity could produce beneficial effects on CNS myelination and promotes motor functions, and if so, what is the underlying mechanism? To address this question, the present study investigated the impact of voluntary wheel running (VWR) on the myelination of the CNS, especially in the motor cortex. We demonstrated that VWR significantly enhances the myelination and motor coordination ability via inhibiting Wnt signaling in oligodendroglial lineage cells.

\section{Methods}

\section{Experimental animals}

C57BL/6 J male mice (8-week old) were kept on a $12 \mathrm{~h}$ light/dark cycle in a temperature-controlled room $\left(25^{\circ} \mathrm{C}\right)$. All mice were individually housed in a light and humidity controlled climatic chamber (SPF condition), fed with HEPA-filtered air, and provided with irradiated food and water. Mice were provided with a regular chow diet (Lab Diets, \#5001). For voluntary-wheel running, mice were housed in cages containing a 5-in. running wheel. Wheel running was entirely voluntary, and no means were used to promote or ensure activity [18]. Control mice were housed in similar cages except that the wheel was locked. All animal procedures were carried out in accordance with the principles of laboratory animal care and use approved by the Nanchang Animal Care and Use Committee guidelines.

\section{Protein extraction and western blotting}

Lysates were generated using RIPA buffer (Thermo Scientific) supplemented with $1 \%$ protease inhibitor cocktail set III EDTA-free (vol/vol, Calbiochem). Samples were heated at $100{ }^{\circ} \mathrm{C}$ for $10 \mathrm{~min}$, and $10 \mu \mathrm{g}$ of total protein was loaded onto $12 \%$ acrylamide gel. Proteins were then transferred onto polyvinylidene difluoride (PVDF) membranes (Millipore). Membranes were blocked with $5 \%$ powdered milk in Tris-buffered saline (TBST) for $2 \mathrm{~h}$ at room temperature on an orbital shaker, and incubated overnight at $4{ }^{\circ} \mathrm{C}$ with primary antibody (see Additional file 1: Table S1 for detail), then washed thrice in TBST for $5 \mathrm{~min}$, and incubated with horseradish peroxidase (HRP)-conjugated IgG secondary antibody (see Additional file 2: Table S2 for details) for $2 \mathrm{~h}$ at room temperature. Chemiluminescent substrate detection using reagent RapidStep ECL Reagent (Thermo) and autoradiography film processing was performed, followed by analysis with Image J (NIH, http:// imagej.nih.gov/ij).

\section{Quantitative real-time PCR (qRT-PCR) analysis}

Total RNA was isolated from snap-frozen brain tissue using Trizol (Invitrogen) according to the manufacturer's protocol. First strand cDNA was synthesized from total RNA using primers and SuperScriptIII reverse transcriptase (Invitrogen). Quantitative real-time PCR (qRT-PCR) was carried out using the ABI Prism 7700 Sequence Detection System and SYBR Green Master Mix according to the manufacturer's directions (Applied Biosystems). Relative mRNA expression levels were calculated via a comparative threshold cycle $\left(\mathrm{C}_{t}\right)$ method using GAPDH as an internal control: $\triangle \mathrm{Ct}=\mathrm{C}_{\mathrm{t}}$ (gene of interest) $-\mathrm{C}_{\mathrm{t}}$ (GAPDH). Gene expression fold change was normalized to control sample and then calculated as $2^{-\Delta \mathrm{Ct}}$. Primers used for qRT-PCR were listed in Additional file 3: Table S3.

\section{Immunohistochemistry and laser confocal scanning} Mice were administered ketamine and xylazine $(150 \mathrm{mg} / \mathrm{kg}$ and $10 \mathrm{mg} / \mathrm{kg}$, respectively) and perfused with $0.1 \mathrm{MPB}$ followed by ice-cold $4 \%$ paraformaldehyde (PFA). Brains were postfixed in $4 \%$ PFA overnight at $4{ }^{\circ} \mathrm{C}$. Brain tissues were cryoprotected in 10, 20,30\% (w/v) sucrose (Sigma) before frozen in optimal cutting temperature compound. Next, Brain slices $(30 \mu \mathrm{m}$ in thickness) were collected and processed as floating slices. Primary antibodies (see Additional file 1: Table S1 for details), the immunoreactivity of which was determined before use, were diluted in blocking solution $(0.1 \%[\mathrm{v} / \mathrm{v}]$ Triton X-100 and $10 \%$ fetal calf serum in $0.01 \mathrm{M}$ PBS) and applied to slices overnight at $4{ }^{\circ} \mathrm{C}$. Negative controls were performed by replacing the primary antibodies with normal rabbit serum. On the next day, brain slides were washed 3 times with PBS and incubated for $2 \mathrm{~h}$ with secondary antibodies (see Additional file 2: Table S2 for details). Finally, brain slices were mounted on slides. Mounted slides were imaged using an inverted laser confocal microscope (FV1000; Olympus). Cells were counted using FV10-ASW (Olympus) and Image J (NIH, http://imagej.nih.gov/ij).

\section{5-bromo-2-deoxyuridine (BrdU) assays}

For cumulative labeling experiments, BrdU (Sigma) was intraperitoneally injected once a day for 2 weeks. Brain slices $(30 \mu \mathrm{m}$ in thickness) were prepared as described above. Brain slices were then washed in PBS and incubated in $0.2 \%$ Triton $\mathrm{X}-100$ in PBS for $1 \mathrm{~h}$ at $20-25^{\circ} \mathrm{C}$. DNA was denatured by two successive incubation steps (10 min each step in $2 \mathrm{~N} \mathrm{HCl}$ ) and neutralized by two successive incubations (10 min each step in $0.1 \mathrm{M}$ sodium tetraborate with $\mathrm{pH}$ 8.5). Then, immunohistochemistry and laser confocal scanning were conducted as described above.

\section{Expression of Wnt3a and Wnt9a in HEK293 cells}

Expression of Wnt3a and Wnt9a in HEK293 cells was performed as described previously [19]. In brief, wellprepared pcDNA3-FLAG-Wnt3a/Wnt9a or p3xFLAG vector plasmid were transfected into HEK293T cells by polyethylenimine (PEI). 6-8 h later, the cultured medium was changed with free-serum conditional medium and left 
overnight. Then, the cell lysis and part of conditional medium were used to detect the proteins of Wnts by western blotting.

\section{Culture of OPCs and Wnt3a/9a treatment}

Oligodendrocyte precursor cells (OPCs) were cultured according to the previous method [20], but with a little modification. Briefly, brain cortical tissues was isolated from postnatal 2-day's rat pups and dissociated by trypsin $(0.25 \%)$. Cortical cells were plated in PDL $(0.1 \mathrm{mg} /$ $\mathrm{ml}$ ) pre-coated T25 flask incubator with $5 \% \mathrm{CO}_{2}$ at $37{ }^{\circ} \mathrm{C}$. OPCs were isolated and cultured in serum-free oligodendrocyte growth medium supplemented with bFGF and PDGF-AA. The conditional medium containing previously-collected Wnts were added into the growth medium. Cortical cells were treated for 4 days in $37{ }^{\circ} \mathrm{C}$ incubator containing $5 \% \mathrm{CO}_{2}$, fixed and finally immunohistochemically stained as described above. As the number of cortical OPCs was more, and the status of the OPCs was better in rat than in mouse, we therefore used rat instead of mouse for this experiment.

\section{Electron microscopy investigation}

Mice were perfused with $0.1 \mathrm{M} \mathrm{PB}$ followed by $2 \%$ gluteraldehyde/4\% PFA in sodium cacodylate buffer. A block of tissue (approximately $1 \times 1 \times 2 \mathrm{~mm}^{3}$ ) from the motor cortex was dissected and postfixed overnight at $4{ }^{\circ} \mathrm{C}$. Brain tissue was dehydrated in an ethanol gradient from 50\% through 100\%, and embedded in Epon. Brain tissue was cut into ultra-thin slices $(70 \mathrm{~nm}$ in thickness). Brain slices were stained with $2 \%$ uranyl acetate $(\mathrm{v} / \mathrm{v})$ and Reynolds lead citrate, and examined with a transmission electron microscope (Hitachi) [21]. The G-ratio, which reflects the thickness of myelin, was determined using the formula as follows: G-ratio $=$ [axonal diameter (without myelin sheath) $\div$ fiber diameter (axon+myelin sheath)].

\section{Open-field test}

Mice were habituated in the experimental room for $1 \mathrm{~h}$ prior to test. Open-field test was used to assess gross locomotion ability [8]. Briefly, each mouse was placed in a $45 \times 45 \mathrm{~cm}^{2}$ open-field arena, and its locomotion activities was recorded for $10 \mathrm{~min}$ using video capture software. Total locomotion distance and velocity were measured. The open field arena was cleaned with $70 \%$ ethanol before used for the next animal.

\section{Rotarod-running test}

We used the rotarod to assess the sensorimotor balance and coordination abilities of mice as described previously $[22,23]$. Briefly, mice were pre-trained on the rod at 10 rpm for 5 min on Day 1. On the next day, mice were placed on the rod and the rotating velocity of the rod was set at $4 \mathrm{rpm}$ at the very beginning, and accelerated to 40 $\mathrm{rpm}$ in $300 \mathrm{~s}$. The test included 4 trials in total, with an inter-trial interval of $5 \mathrm{~min}$. The time to fall down from the rotating rod was recorded for each mouse.

\section{Beam-walking test}

Beam-walking test was a second paradigm assessing the sensorimotor balance and coordination ability [22]. Mice were required to walk on a square wood beam with $6 \mathrm{~mm}$ in width, $80 \mathrm{~cm}$ in length and $30 \mathrm{~cm}$ apart from the ground. Mice were pre-trained to walk on the beam. On the next day, the formal training was performed and include 3 trials. Each trial started by placing mice on one end of the beam. Mice were required to walk to the other end of the beam, and to enter into a black box (safe place). The total number of foot slips during the beam-walking process was collected.

\section{Statistical analysis}

All statistical analyses including testing the normality of data distribution were performed using GraphPad Prism 6 and $p$ value $<0.05$ was considered as significant difference. For comparing difference between 2 groups with normally distributed datasets, unpaired Student's t-test was used. Correlation analysis were assessed using Pearson's rank correlation test.

\section{Results \\ VWR promotes myelination in the motor cortex}

To administer voluntary wheel running (VWR), we used a voluntary running task in which mice were given unrestricted access to a monitored running wheel for 2 weeks (Fig. 1a). VWR mice were individually housed in modified cages, with each cage containing a 5-in. running wheel. Control mice were housed in an identical setting, with a locked wheel. After 2-week voluntary running, the VWR mice exhibited a similar body weight and brain weight with the control mice (Fig. 1b-d).

To evaluate the effect of VWR on myelination, we first examined the mRNA and protein levels of myelin basic protein (MBP) in three different brain regions related to motor function. As shown in Fig. 1e-g, the VWR mice demonstrated a significant increase in the mRNA and protein levels of MBP in the motor cortex, but not in the corpus callosum and striatum relative to controls. Consistently, immunohistochemistry for MBP showed that VWR mice displayed a markedly enhanced myelination in the motor cortex, but not in the corpus callosum and striatum relative to controls (Fig. 1h-k). Regression analysis revealed a significant correlation between running distance with relative MBP fluorescence intensity in the motor cortex in individual VWR mice (Fig. $1 \mathrm{l}$ and $\mathrm{m}$ ). This result indicates that VWR could promote the myelination of the motor cortex.

To further confirm that VWR could promote myelination, we performed electron microscopy analysis in the motor cortex (Fig. 2a). A significant increase in 


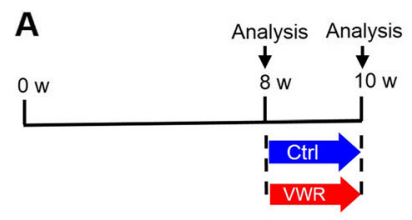

E
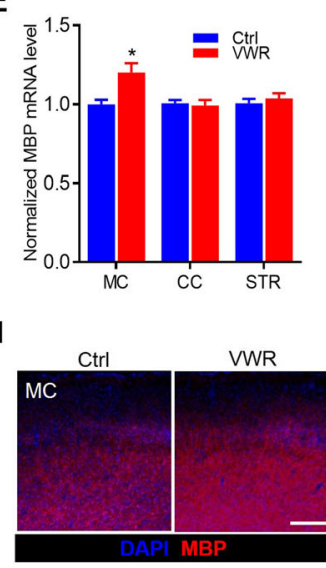

K

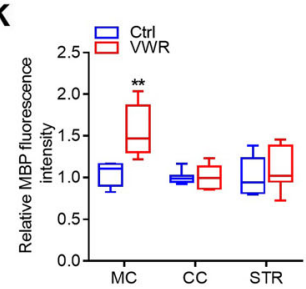

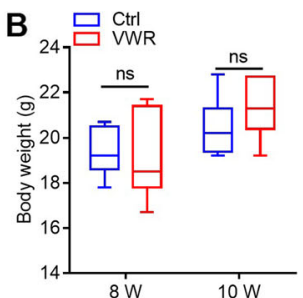
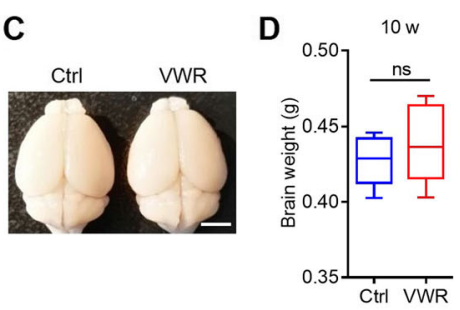

$\mathbf{F}$

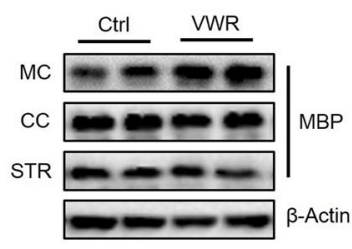

G

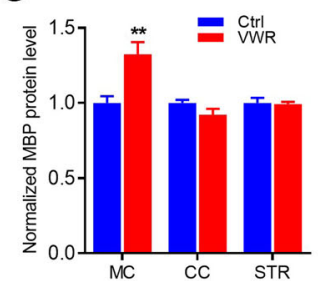

I
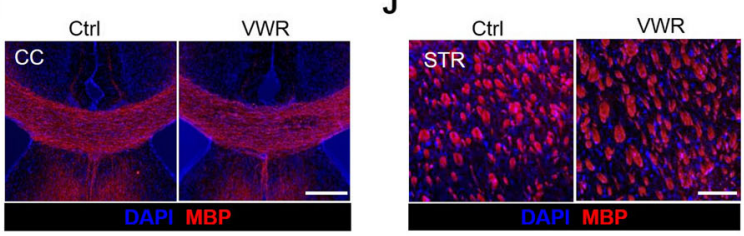

M

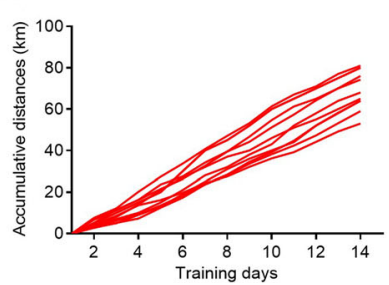

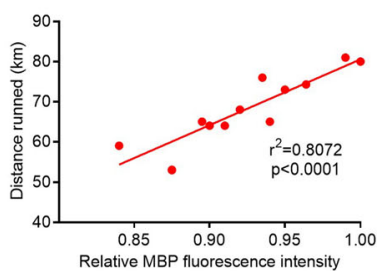

Fig. 1 Voluntary wheel running (MVR) accelerates myelination in the motor cortex. a Time course schema for animal treatment and testing. $\mathbf{b}$ Body weight of Control (Ctrl) and WWR mice. $n=7$ per group. ns, $p>0.05$, unpaired Student's t-test. c Brains removed from Ctrl and WWR mice. Scale bar $=5 \mathrm{~mm}$. $\mathbf{d}$ Brain weight of Ctrl and WWR mice. $n=7$ per group. $n s, p>0.05$, unpaired Student's t-test. e mRNA levels of MBP in different brain regions of Ctrl and WWR mice. $n=6$ per group. ${ }^{*} p<0.05$ vs Ctrl, unpaired Student's t-test. $\mathbf{f}, \mathbf{g}$ Protein levels of MBP in different brain regions of Ctrl and WWR mice. $n=6$ per group. ${ }^{* *} p<0.01$ vs Ctrl, unpaired Student's t-test. $\mathbf{h}-\mathbf{j}$ Confocal images of MBP staining in different brain regions of Ctrl and WWR mice. Scale bar $=500 \mu \mathrm{m}$. $\mathbf{k}$ Quantitative analysis of the relative MBP fluorescent intensity in different brain regions of Ctrl and WWR mice. $n=7$ per group. ${ }^{* *} p<0.01$ vs Ctrl, unpaired Student's t-test. I Accumulative running distances on the wheel of individual mice with training. $\mathbf{m}$ Correlation analysis between relative MBP fluorescence intensity in the motor cortex and running distances. Data are presented as mean \pm SEM or minimum to maximum. MC, motor cortex; CC, corpus callosum; STR, striatum

the number of myelinated axons (Fig. 2b) and the thickness of myelin was observed in the motor cortex of the VWR mice, as evidenced by the decreased average G-ratio (Fig. 2c, d), while the diameter of axons kept unchanged (Fig. 2e).

Taken together, these results provide solid evidence for a substantial beneficial effect of VWR on promoting myelination in the motor cortex.

\section{VWR enhances OPCs proliferation and differentiationin the motor cortex}

OPCs (PDGFR $\alpha^{+} \mathrm{Olig}^{+}$) arise from neuroepithelial progenitors in the ventral neural tube, and they migrate, proliferate, and ultimately differentiate to form mature OLs $\left(\mathrm{CC}^{+}\right.$Olig2 $\left.{ }^{+}\right)$[24-27]. Thus, we analyzed the density of OPCs and OLs in the motor cortex by immunohistochemistry. As shown in Fig. 3, the density of OPCs was not affected by VWR (Fig. 3a, c), while oligodendroglial lineage cells $\left(\mathrm{Olig}^{+}\right)$and mature OLs significantly increased in VWR mice (Fig. 3b, $d$ and e). To determine if OPCs proliferation was up-regulated, we examined the profile of OPCs proliferation. Mice were administered BrdU from 8- to 10-week old (once a day), and cumulative BrdU incorporation was measured at 10week old. A significant increase of newly generated OPCs $\left(\mathrm{BrdU}^{+} \mathrm{NG}^{+}\right.$) was observed in VWR mice (Fig. 3f and g). 
A
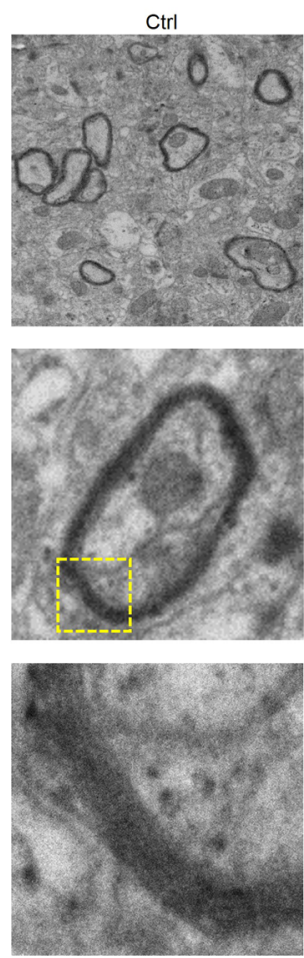
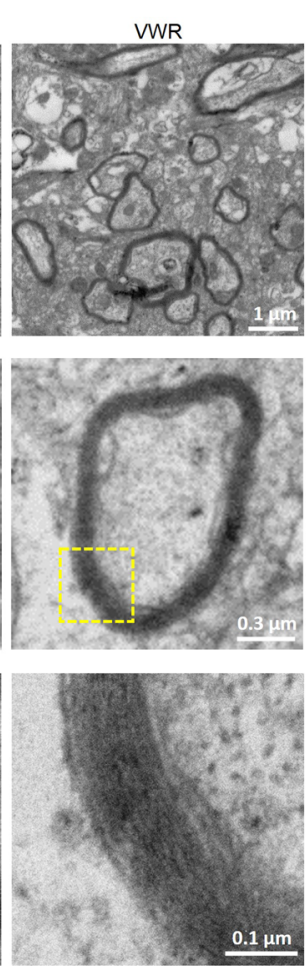

B

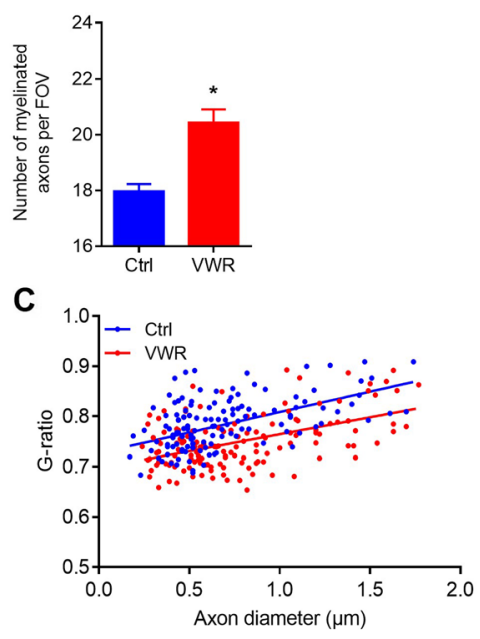

D

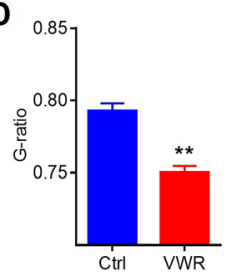

E

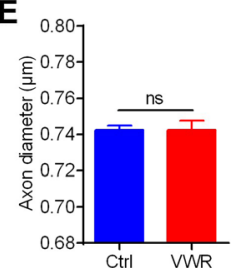

Fig. 2 Voluntary wheel running (WWR) increases the number and the thickness of myelinated axons in the motor cortex. a Representative electron micrographs of axon and myelin in control (Ctrl) and WWR mice. $\mathbf{b}$ Quantification of myelinated axons per field of view $\left(\mathrm{FOV}=506 \mu \mathrm{m}^{2}\right)$ in Ctrl and WWR mice. c, d G-ratio analysis for the thickness of myelin in Ctrl and WWR mice. e Diameter of axons in Ctrl and WWR mice. For electron microscopy, enough independent fields were quantified to achieve at least 150 axons per group. Data are presented as mean \pm SEM. $n=150$ from3 mice per group. ${ }^{*} p<0.05$ vs Ctrl; ${ }^{* *} p<0.01$ vs Ctrl; ns, $p>0.05$, unpaired Student's t-test and Pearson's rank correlation test

Thus, VWR could promote OPCs proliferation and dramatically increase the number of mature OLs in the motor cortex.

\section{VWR promotes motor coordination performance}

To evaluate motor ability change associated with VWRenhanced oligodendrogenesis and myelination in the motor cortex, we measured gross motor function and fine motor coordination ability using open-field, rotarodrunning and beam-walking tests. As shown in Fig. 4, the total distance travelled and the average locomotion speed in the open field test were not changed in the VWR mice (Fig. 4a and b). However, the VWR mice ran significantly longer in the rotating rotarod, and displayed less foot slips in the beam-walking test relative to the controls (Fig. 4c, d). This result suggest that VWR could promote fine motor coordination ability.

\section{VWR promotes myelination via Wnt signaling pathway}

Previous studies have demonstrated that canonical Wnt signaling functions as a potent inhibitor of OPCs differentiation [28]. Activation of Wnt signaling decreases the phosphorylation of $\beta$-catenin by glycogen synthase kinase $3 \beta($ GSK-3 $\beta)$ and thus prevents $\beta$-catenin degradation. Then, $\beta$-catenin competes with HDAC1 and/or HDAC2 to interact with TCF7L2 to inhibit OPCs differentiation $[21,28,29]$. To determine if the VWRenhanced myelination involved Wnt signaling, we assessed the protein levels of GSK-3 $\beta, \beta$-catenin and phosphorylated $\beta$-catenin ( $\mathrm{p}-\beta$-catenin) in the motor cortex using western blotting. We found that the levels of GSK-3 $\beta$ and $\beta$-catenin were not changed in VWR mice (Fig. $5 \mathrm{a}-\mathrm{c}$ ), whereas the level of p- $\beta$-catenin markedly increased (Fig. 5b, d). Furthermore, we used immunohistochemistry and found that $\mathrm{p}-\beta$-catenin-positive OPCs $\left(\mathrm{PDGFR \alpha} \alpha^{+}\right)$and OLs $\left(\mathrm{CC}^{+}\right)$significantly increased in VWR mice (Fig. 5e-h).

In order to understand the mechanism through which VWR activates Wnt signaling, we detected the changes of the transcripts of Wnts. We isolated the tissue of the motor cortex using microdissection and conducted qRTPCR analysis to evaluate the mRNA levels of different Wnts. As shown in Fig. 6, the mRNA levels of Wnt3a and $W n t 9 a$ in the motor cortex was dramatically downregulated in VWR mice (Fig. 6a). To demonstrate the role of $W n t 3 a$ and $W n t 9 a$ in the proliferation and differentiation of OPCs, we expressed and purified Wnt3a 


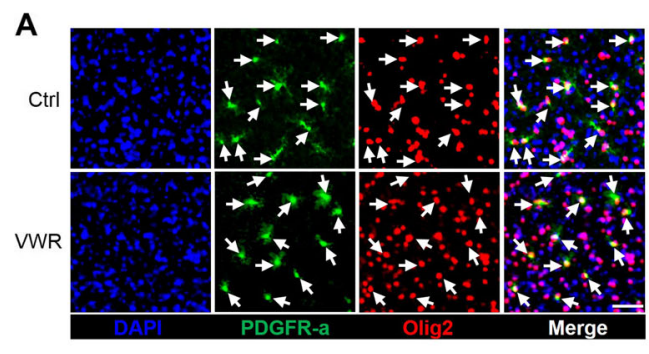

B
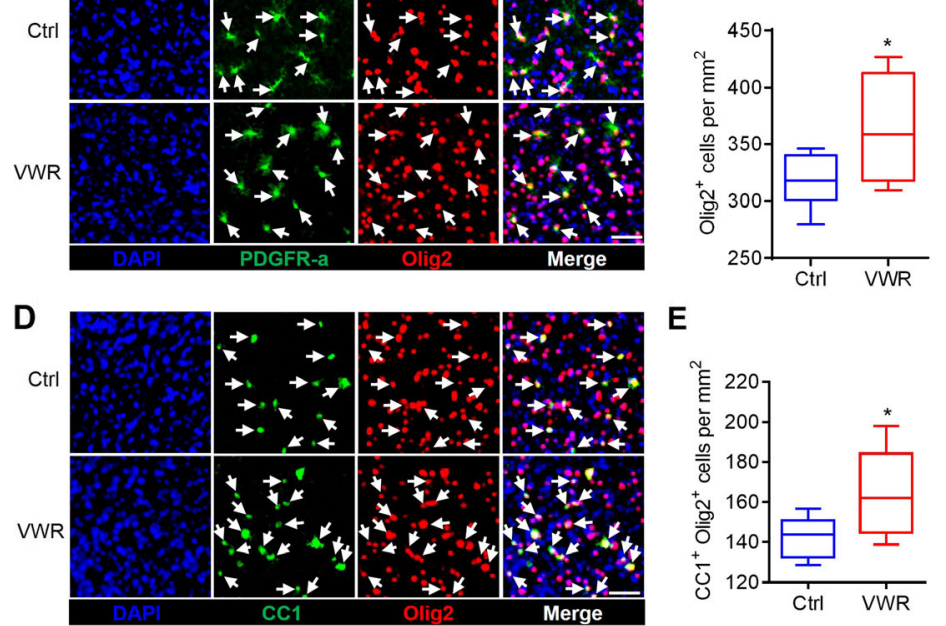

E
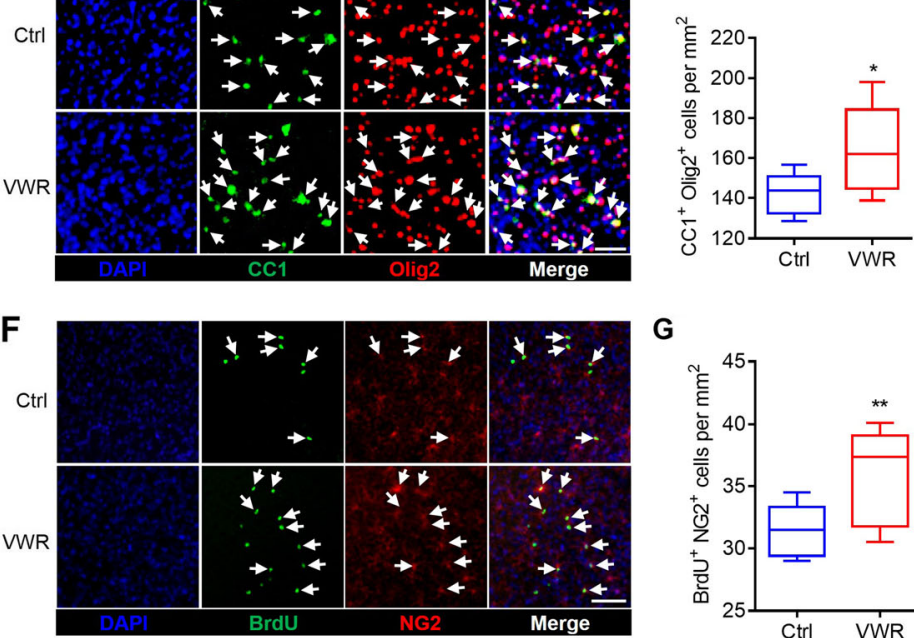

\section{G}

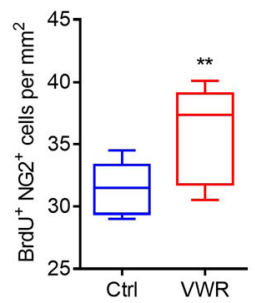

C

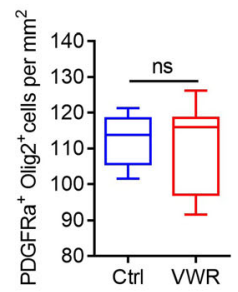

Fig. 3 Voluntary wheel running (VWR) accelerates OPC proliferation and OL maturation in the motor cortex. a Confocal images of PDGFRa- and Olig2-possive cells in the motor cortex of control (Ctrl) and WWR mice. Scale bar $=50 \mu \mathrm{m}$. b WWR mice have significantly more oligodendroglial lineage cells (Olig2 ${ }^{+}$) than Ctrl mice. c WWR mice have statistically equal number of OPCs (PDGFRa ${ }^{+}$Olig2 ${ }^{+}$) as control mice. $\mathbf{d}$ Confocal images of CC1- and Olig2-positive cells in the motor cortex of Ctrl and WWR mice. Scale bar $=40 \mu \mathrm{m}$. e WWR mice have significantly more mature OLs $\left(\mathrm{CC}^{+} \mathrm{Olig}^{+}\right)$than Ctrl mice. $\mathbf{f}$ Confocal images of BrdU- and NG2-positive cells in the motor cortex of Ctrl and WWR mice. Scale bar $=60 \mu \mathrm{m} . \mathbf{g}$ WWR mice have significantly more newly generated OPCs $\left(\mathrm{NG}_{2}{ }^{B} \mathrm{BrdU}^{+}\right)$than $\mathrm{Ctrl}$ mice. Data are presented as minimum to maximum. $n=8$ per group. ${ }^{*} p<0.05$ vs Ctrl; ns, $p>0.05 ;{ }^{* *} p<0.01$ vs Ctrl; unpaired Student's t-test

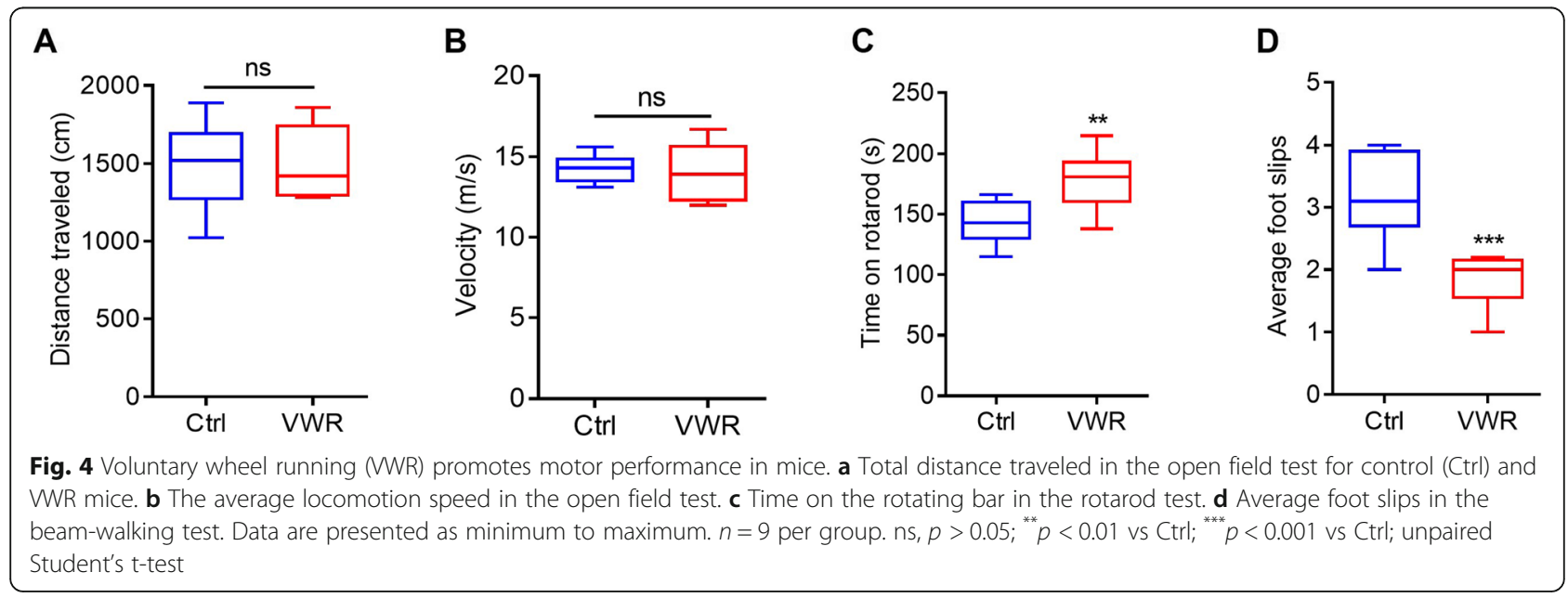




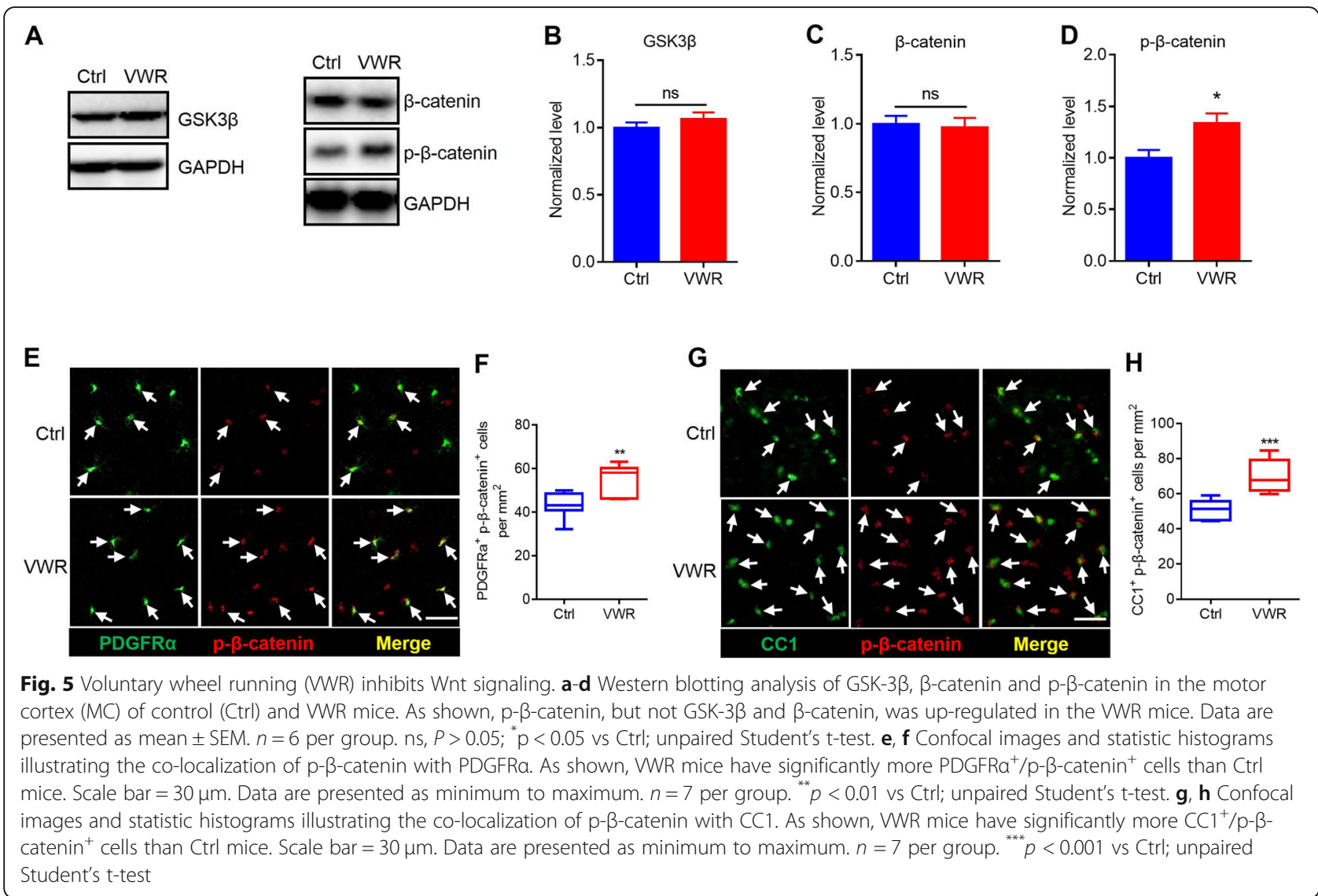

and Wnt9a from HEK293 cell in culture (Fig. 6b). We then developed an imaging assay based on the induction of MBP expression in rat cortex-derived OPCs cultured for 4 days under basal differentiation conditions. We found that Wnt3a and Wnt9a treatment significantly decreased the number of OPCs (Fig. $6 \mathrm{c}$ and $\mathrm{d}$ ) and impaired the efficient differentiation of OPCs into MBPproducing mature oligodendrocytes (Fig. 6e and f).

Taken together, these results suggest that VWR promotes OPCs proliferation and differentiation and ultimately the myelination of the motor cortex, most likely by inhibiting Wnt signaling.

\section{Discussion}

The present study demonstrated that voluntary wheel running promotes the proliferation and differentiation of OPCs and thus enhances the myelination in the motor cortex, and such beneficial effect is probably mediated via Wnt signaling.

It has been documented that central myelination have a huge potential of plasticity [30-32]. In humans, central myelination continues throughout adolescence and adulthood [5, 33, 34]. White matter development correlates with enhanced motor skills, reading ability and cognitive functions [31, 35]. Learning sensorimotor skills, studying a new language, or undertaking working memory training induces structural change in the white matter and promotes oligodendrogenesis and adaptive myelination in the brain [36-39]. On the other hand, some neuropsychiatric diseases, such as amyotrophic lateral sclerosis, bipolar disorder and schizophrenia, are associated with defects in central myelination [40-44]. Social deprivation or chronic stress results in hypomyelination in the prefrontal cortex, and impairs social interaction ability in mice [45-47]. A previous study in our laboratory revealed that neonatal maternal separation hinders mPFC myelination in rats and impairs mPFC-dependent functions [21]. The present study adds new evidence for the plasticity nature of cerebral myelination, and indicates the role that individual experience has in regulating cerebral myelination.

The existence of an activity-driven myelination has been postulated [31, 32]. Previous studies in rodents show that running skill training or feeding skill training promotes the myelination in related brain regions [48, 49]. Even voluntary running could also promote the differentiation of OPCs in the sensorimotor cortex [50], and accelerate the proliferation of OPCs in the spinal cord [51]. Consistently, the present study demonstrated 


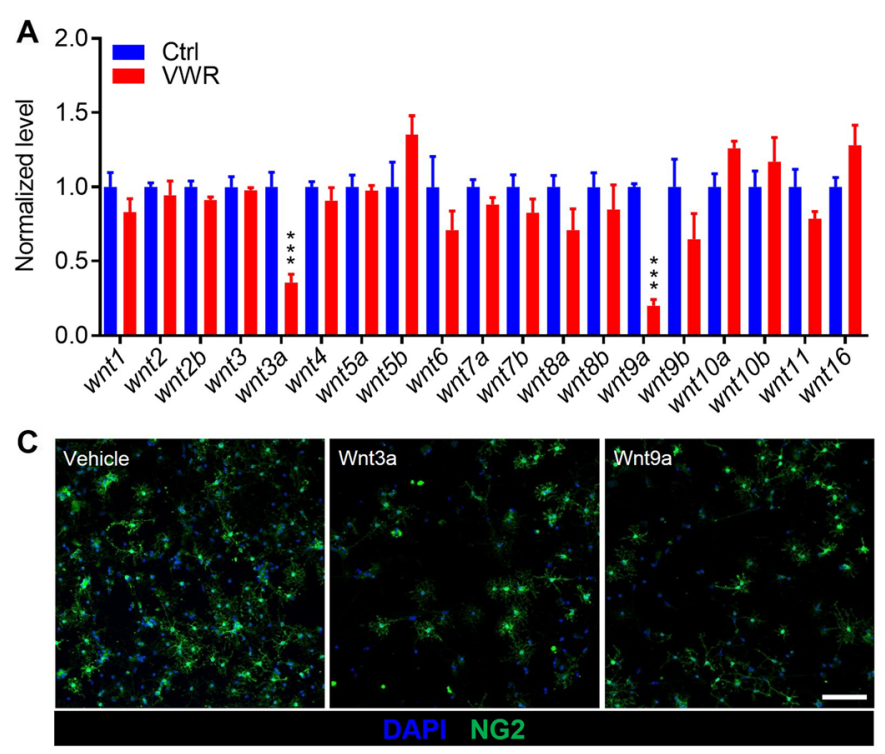

B

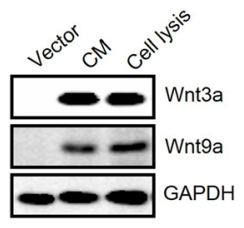

E
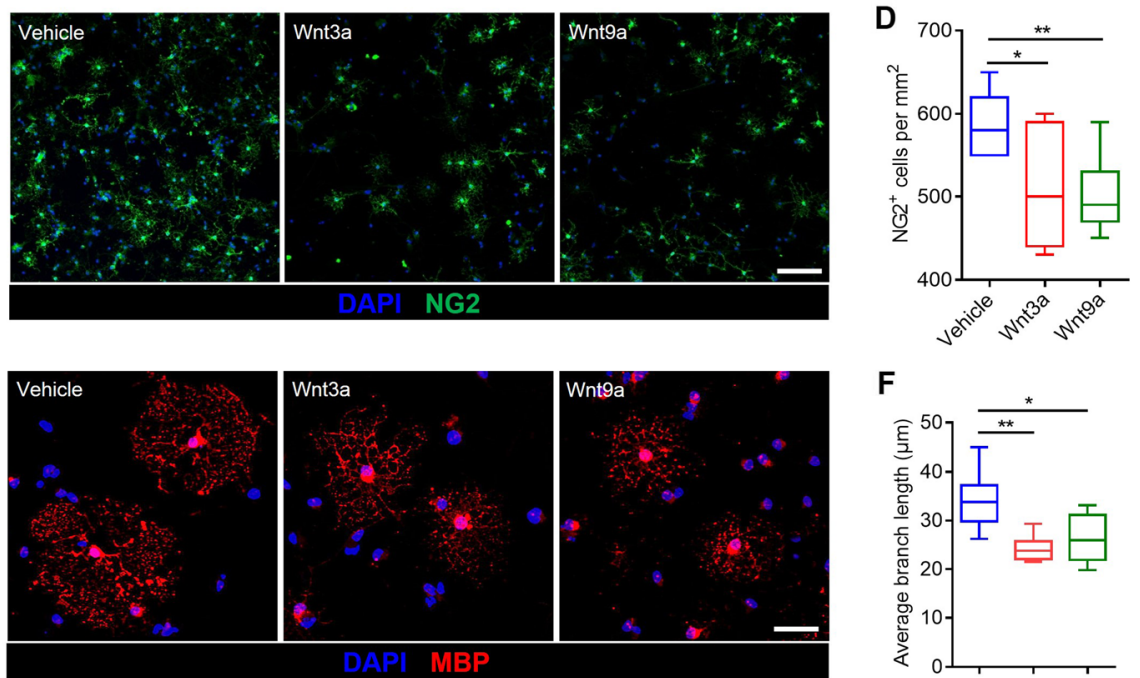

$\mathbf{F}$

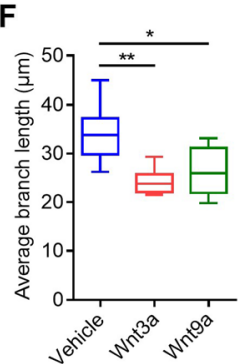

Fig. 6 Voluntary wheel running (WWR) promotes myelination via inhibiting the expression of Wnt3a and Wnt9a. a The mRNA levels of Wnts in the motor cortex of control (Ctrl) and WWR mice. Data are presented as mean \pm SEM. $n=6$ per group; ${ }^{* * *} p<0.001$ vs Ctrl, unpaired Student's t-test. $\mathbf{b}$ Expression of Wnt3a and Wnt9a in HEK293 cells. CM, Cell membrane. c, d Wnt3a- and Wnt9a-treated OPCs immunostained for NG2 (OPCs). As shown, the number of OPCs decreased upon treatment with Wnt3a or Wnt9a. Scale bar $=20 \mu \mathrm{m}$. Data are presented as minimum to maximum. $n=7$ independent coverslips per condition. ${ }^{*} p<0.05$ vs Ctrl; ${ }^{* *} p<0.01$ vs Ctrl; unpaired Student's t-test. e, f Wnt3a- and Wnt9a-treated OPCs immunostained for MBP (OLs). The average branch length of OLs decreased upon treatment with Wnt3a or Wnt9a. Scale bars $=20 \mu \mathrm{m}$. Data are presented as minimum to maximum. $n=7$ independent coverslips per condition. ${ }^{* *} p<0.01$ vs Ctrl; $p<0.05$ vs Ctrl; unpaired Student's t-test

that OPCs and myelin in the motor cortex were both affected by physical activity like voluntary wheel running.

It is known that physical activity accelerates myelination through an increase in OPCs proliferation and differentiation $[48,52]$. The present study found that VWR promoted the proliferation and differentiation of OPCs and the maturation of OLs, and enhanced the myelination in the motor cortex. The VWR-enhanced myelination was associated with improved motor skills. More importantly, we found that the VWR-enhanced myelination was linked with a significant decrease in the level of Wnt3a and Wnt9a, and a significant increase in the level of $\mathrm{p}$ - $\beta$-catenin, the key molecules in the Wnt signaling pathway. Moreover, stimulation of Wnt signaling pathway with Wnt3a or Wnt9a suppresses OPCs proliferation and differentiation in culture. Our findings provide insight into the signaling mechanism underlying the VWR-enhanced myelination in the motor cortex.
In summary, the present study demonstrated that physical activity is highly efficient at promoting myelination by enhancing the proliferation of OPCs and accelerating the generation of myelin in the motor cortex, providing a step forward in understanding the beneficial effects of physical activity on central myelination and its underlying mechanism.

\section{Supplementary information}

Supplementary information accompanies this paper at https://doi.org/10 1186/s13041-019-0506-8

Additional file 1: Table S1. Source and dilution of primary antibodies. Additional file 2: Table S2. Source and dilution of secondary antibodies. Additional file 3: Table S3. Primers used in the present study.

Acknowledgments Not applicable. 


\section{Authors' contributions}

$\mathrm{BL}$ and $\mathrm{JZ}$ designed the research and wrote the manuscript; JZ, XS and FL performed experiments and analyzed the data; CM provided useful suggestions. All authors read and approved the final manuscript.

\section{Funding}

This study was supported by the National Natural Science Foundation of China $(81471116$ and 31771182,81560196$)$ and the Natural Science Foundation of Jiangxi Province (20171ACB20002)

\section{Availability of data and materials}

The data generated or analyzed are included in this published article.

\section{Ethics approva}

All experiments were approved by the Nanchang Animal Care and Use Committee and conducted according to the Guidelines for the Care and Use of Laboratory Animals.

\section{Consent for publication}

Not applicable.

\section{Competing interests}

The authors declare that they have no competing interests.

\section{Author details}

'Institute of Life Science, Nanchang University, Nanchang 330031, China. ${ }^{2}$ School of Basic Medical Sciences, Nanchang University, Nanchang 330006, China.

\section{Received: 30 July 2019 Accepted: 1 October 2019}

Published online: 24 October 2019

\section{References}

1. Chang KJ, Redmond SA, Chan JR. Remodeling myelination: implications for mechanisms of neural plasticity. Nat Neurosci. 2016;19:190-7.

2. Hartline DK, Colman DR. Rapid conduction and the evolution of Giant axons and Myelinated fibers. Current Biology Cb. 2007:17:R29-35.

3. Lebel C, Gee M, Camicioli R, Wieler M, Martin W, Beaulieu C. Diffusion tensor imaging of white matter tract evolution over the lifespan. Neuroimage. 2012;60:340-52.

4. Miller DJ, Duka T, Stimpson CD, Schapiro SJ, Baze WB, McArthur MJ, et al. Prolonged myelination in human neocortical evolution. P Natl Acad Sci USA. 2012;109:16480-5.

5. Fields D, Myelination R. An overlooked mechanism of synaptic plasticity? Neuroscientist. 2005;11:528-31

6. Zatorre RJ, Fields RD, Johansen-Berg H. Plasticity in gray and white: neuroimaging changes in brain structure during learning. Nat Neurosci. 2012;15:528

7. Emery B. Regulation of Oligodendrocyte differentiation and Myelination. Science. 2010:330:779-82.

8. Nave K-A. Myelination and support of axonal integrity by glia. Nature. 2010; 468:244.

9. Mattson MP. Energy intake and exercise as determinants of brain health and vulnerability to injury and disease. Cell Metab. 2012;16:706-22.

10. Cotman CW. Exercise : a behavioral intervention to enhance brain health and plasticity. Trends Neurosci. 2002;25:295-301.

11. Cotman CW, Berchtold NC, Christie L. Exercise builds brain health: key roles of growth factor cascades and inflammation. Trends Neurosci. 2007;30:464-72.

12. Praag HV, Kempermann G, Gage FH. Running increases cell proliferation and neurogenesis in the adult mouse dentate gyrus. Nat Neurosci. 1999;2:266-70.

13. Praag HV, Shubert T, Zhao C, Gage FH. Exercise enhances learning and hippocampal neurogenesis in aged mice. J Neurosci. 2005;25:8680.

14. Kannangara TS, Lucero MJ, Gil-Mohapel J, Drapala RJ, Simpson JM, Christie $\mathrm{BR}$, et al. Running reduces stress and enhances cell genesis in aged mice. Neurobiol Aging. 2011;32:2279-86.

15. Valdez G, Tapia JC, Kang H, Clemenson GD, Gage FH, Lichtman JW, et al. Attenuation of age-related changes in mouse neuromuscular synapses by caloric restriction and exercise. P Natl Acad Sci USA. 2010;107:14863-8.

16. Villeda SA, Luo J, Mosher Kl, Zou B, Britschgi M, Bieri G, et al. The ageing systemic milieu negatively regulates neurogenesis and cognitive function. Nature. 2011;477:90-4.
17. Fuss J, Abdallah NMB, Vogt MA, Pacifici PG, Palme R, Witzemann V, et al. Voluntary exercise induces anxiety-like behavior in adult C57BL/6 J mice correlating with hippocampal neurogenesis. Hippocampus. 2010; 20:364-76.

18. Chowdhury TG, Wable GS, Chen YW, Tateyama K, Yu I, Wang JY, et al. Voluntary wheel running exercise evoked by food-restriction stress exacerbates weight loss of adolescent female rats but also promotes resilience by enhancing gabaergic inhibition of pyramidal neurons in the dorsal hippocampus. Cereb Cortex. 2018;29(10):4035.

19. Shimizu T, Kagawa T, Wada T, Muroyama Y, Takada S, Ikenaka K. Wnt signaling controls the timing of oligodendrocyte development in the spinal cord. Dev Biol. 2005;282:397-410.

20. Chen Y, Balasubramaniyan V, Peng J, Hurlock EC, Tallquist M, Li J, et al. Isolation and culture of rat and mouse oligodendrocyte precursor cells. Nat Protoc. 2007:2:1044-51.

21. Yang Y, Cheng Z, Tang H, Jiao H, Sun X, Cui Q, et al. Neonatal maternal separation impairs prefrontal cortical Myelination and cognitive functions in rats through activation of Wnt signaling. Cereb Cortex. 2017;27:2871.

22. Brickler TR, Hazy A, Guilhaume CF, Dai R, Kowalski E, Dickerson R, et al. Angiopoietin/Tie2 Axis regulates the age-at-injury cerebrovascular response to traumatic brain injury. J Neurosci. 2018;38:9618-34.

23. Xia Y, Pu H, Leak RK, Shi Y, Mu H, Hu X, et al. Tissue plasminogen activator promotes white matter integrity and functional recovery in a murine model of traumatic brain injury. Proc Natl Acad Sci U S A. 2018;115:E9230-8.

24. Hughes EG, Kang SH, Fukaya M, Bergles DE. Oligodendrocyte progenitors balance growth with self-repulsion to achieve homeostasis in the adult brain. Nat Neurosci. 2013;16:668-76.

25. Young KM, Psachoulia K, Tripathi RB, Dunn SJ, Richardson WD. Oligodendrocyte dynamics in the healthy adult CNS: evidence for myelin remodeling. Neuron. 2013:77:873-85.

26. Dimou L, Gallo V. NG2-glia and their functions in the central nervous system. Glia. 2015:63:1429-51.

27. Bergles DE, Richardson WD. Oligodendrocyte development and plasticity. CSH Perspect Biol. 2016:8:a20453.

28. Fancy SPJ, Baranzini SE, Zhao C, Yuk DI, Irvine KA, Kaing S, et al. Dysregulation of the Wnt pathway inhibits timely myelination and remyelination in the mammalian CNS. Genes Dev. 2009;23:1571.

29. Ye F, Chen Y, Hoang TN, Montgomery RL, Lu QR. HDAC1 and HDAC2 regulate oligodendrocyte differentiation by disrupting the B-catenin-TCF interaction. Nat Neurosci. 2009;12:829-38.

30. Tomassy GS, Dershowitz LB, Arlotta P. Diversity matters: a revised guide to myelination. Trends Cell Biol. 2016;26:135-47.

31. Mount CW, Monje M. Wrapped to adapt: experience-dependent Myelination. Neuron. 2017;95:743-56.

32. Forbes TA, Gallo V. All wrapped up: environmental effects on Myelination. Trends Neurosci. 2017:40:S206988544

33. Michelle M. Myelin plasticity and nervous system function. Annu Rev Neurosci. 2018;41:61

34. Purger D, Gibson EM, Monje M. Myelin plasticity in the central nervous system. Neuropharmacology. 2016;110:563-73

35. Tomlinson L, Leiton CV, Colognato H. Behavioral experiences as drivers of oligodendrocyte lineage dynamics and myelin plasticity. Neuropharmacology. 2016:110:548-62.

36. Scholz J, Klein MC, Behrens TEJ, Johansen-Berg H. Training induces changes in white-matter architecture. Nat Neurosci. 2009:12:1370-1.

37. Hosoda C, Tanaka K, Nariai T, Honda M, Hanakawa T. Dynamic neural network reorganization associated with second language vocabulary acquisition: a multimodal imaging study. J Neurosci. 2013;33:13663-72.

38. Mohades SG, Struys E, Van Schuerbeek P, Mondt K, Van De Craen P, Luypaert R. DTI reveals structural differences in white matter tracts between bilingual and monolingual children. Brain Res. 2012;1435:72-80.

39. Metzler-Baddeley C, Foley S, de Santis S, Charron C, Hampshire A, Caeyenberghs $\mathrm{K}$, et al. Dynamics of white matter plasticity underlying working memory training: multimodal evidence from diffusion MRI and Relaxometry. J Cogn Neurosci. 2017;29:1509-20.

40. Kang SH, Li Y, Fukaya M, Lorenzini I, Cleveland DW, Ostrow LW, et al. Degeneration and impaired regeneration of gray matter oligodendrocytes in amyotrophic lateral sclerosis. Nat Neurosci. 2013:16:571.

41. Lewandowski KE, Ongür D, Sperry SH, Cohen BM, Sehovic S, Goldbach JR, et al. Myelin vs axon abnormalities in white matter in bipolar disorder. Neuropsychopharmacol. 2015;40:1243-9. 
42. Palaniyappan L, Al-Radaideh A, Mougin O, Gowland P, Liddle PF. Combined white matter imaging suggests Myelination defects in visual processing regions in schizophrenia. Neuropsychopharmacol. 2013;38:1808-15.

43. Stedehouder J, Kushner S. Myelination of parvalbumin interneurons: parsimonious locus of pathophysiological convergence in schizophrenia. Mol Psychiatry. 2017;22:4-12

44. Hakak Y, Walker JR, Li C, Wong WH, Davis KL. Genome-wide expression analysis reveals dysregulation of myelination-related genes in chronic schizophrenia. P Natl Acad Sci USA. 2001;98:4746-51.

45. Liu J, Dietz K, DeLoyht JM, Pedre X, Kelkar D, Kaur J, et al. Impaired adult myelination in the prefrontal cortex of socially isolated mice. Nat Neurosci. 2012;15:1621.

46. Makinodan M, Rosen KM, Ito S, Corfas G. A critical period for social experience-dependent Oligodendrocyte maturation and Myelination. Science. 2012;337:1357-60.

47. Yang Y, Zhang Y, Luo F, Li B. Chronic stress regulates NG2+ cell maturation and myelination in the prefrontal cortex through induction of death receptor 6. Exp Neurol. 2016;277:202-14.

48. McKenzie IA. Ohayon D, Li H, Paes De Faria J, Emery B, Tohyama K, et al. motor skill learning requires active central myelination. Science. 2014;346: 318-22.

49. Sampaio-Baptista C, Khrapitchev AA, Foxley S, Schlagheck T, Scholz J, Jbabd $S$, et al. Motor skill learning induces changes in white matter microstructure and Myelination. J Neurosci. 2013;33:19499.

50. Simon C, Tz MG, Dimou L. Progenitors in the adult cerebral cortex: cell cycle properties and regulation by physiological stimuli and injury. Glia. 2011;59: 869-81.

51. Krityakiarana W, Espinosa-Jeffrey A, Ghiani CA, Zhao PM, Topaldjikian N, Gomez-Pinilla F, et al. Voluntary exercise increases Oligodendrogenesis in spinal cord. Int J Neurosci. 2010;120:280-90.

52. Gibson EM, Purger D, Mount CW, Goldstein AK, Lin GL, Wood LS, et al. Neuronal activity promotes Oligodendrogenesis and adaptive Myelination in the mammalian brain. Science. 2014:344:1252304.

\section{Publisher's Note}

Springer Nature remains neutral with regard to jurisdictional claims in published maps and institutional affiliations.

Ready to submit your research? Choose BMC and benefit from:

- fast, convenient online submission

- thorough peer review by experienced researchers in your field

- rapid publication on acceptance

- support for research data, including large and complex data types

- gold Open Access which fosters wider collaboration and increased citations

- maximum visibility for your research: over $100 \mathrm{M}$ website views per year

At $\mathrm{BMC}$, research is always in progress.

Learn more biomedcentral.com/submissions 